\title{
Tribological Characteristics of (TiZrHfVNbTa)N Coatings Applied Using the Vacuum Arc Deposition Method
}

\author{
S. N. Grigoriev ${ }^{a, *}$, O. V. Sobol ${ }^{b}$, V. M. Beresnev ${ }^{c}$, I. V. Serdyuk ${ }^{d}$, A. D. Pogrebnyak ${ }^{e}$, \\ D. A. Kolesnikov $f$ and U. S. Nemchenko ${ }^{c}$ \\ ${ }^{a}$ Moscow State University of Technology STANKIN, Vadkovskii per. 1, Moscow, 127994 Russia \\ ${ }^{b}$ Khar'kovsii Polytechnic Institute National Technical University, ul. Frunze 21, Khar'kov, 61002 Ukraine \\ ${ }^{c}$ Karazin Khar'kov National University, pl. Svobody 4, Khar'kov, 61022 Ukraine \\ ${ }^{d}$ National Science Center Kharkov Institute of Physics and Technology, ul. Akademicheskaya 1, Khar'kov, 61108 Ukraine \\ e Sumi State University, ul. Rimskkogo-Korsakova 2, Sumi, 40007 Ukraine

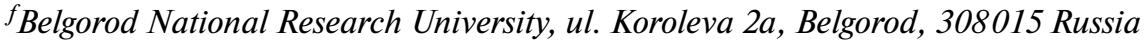 \\ *e-mail: science@stankin.ru \\ Received May 5, 2014
}

\begin{abstract}
The effect of the pressure of the nitrogen atmosphere during the formation of vacuum arc nitride coatings based on high entropy alloys of the $\mathrm{Ti}-\mathrm{Zr}-\mathrm{Hf}-\mathrm{V}-\mathrm{Nb}-\mathrm{Ta}$ system on their structure, hardness, and tribotechnical characteristics is considered. It is shown that strong nitride-forming components lead to the dependence of the structural state and properties on the pressure of the nitrogen atmosphere during coating deposition. Deposition at a nitrogen pressure of $0.4 \mathrm{~Pa}$ results in the formation of a texture with the [111] axis when the applied bias potential is $-70 \mathrm{~V}$ and when the bias potential is equal to $-150 \mathrm{~V}$ the textural structure is biaxial ([111] and [110]) textures and high value of hardness of $51 \mathrm{GPa}$ Along with that the highest value of wear resistance (under oxidizing-mechanical wear) is inherent to coatings formed under the pressure of nitrogen of $0.09 \mathrm{~Pa}$. The strongest microdeformation of coating crystallites corresponds to this pressure.
\end{abstract}

Keywords: vacuum arc deposition method, high entropic alloys, refractory metal nitrides, tribotechnical characteristics

DOI: $10.3103 / \mathrm{S} 1068366614050067$

\section{INTRODUCTION}

During the operation of parts of machines and cutting tool surface layers experience the strongest mechanical and chemical impact; thus, the modification of working surfaces of parts seems to be the most probable. The required results can be achieved by applying multifunctional coatings to working surfaces, which combine high hardness, wear, and thermal resistance [1-7].

The concept of creating a new class of coatings based on multicomponent materials in which highentropy alloys are used as evaporated materials [811]. As a result of intensive mixing, the entropy contribution increases, which stabilizes the formation of a solid solution with a simple structure [12]. The stability of the structure and the composition under high temperatures and the high operating characteristics of multicomponent systems enable the development of nitride and carbide coatings with ability of high microstructure dispersion. The structure and composition stability under high temperatures and high operating characteristics of multicomponent systems make it possible to develop nitride and carbide coatings with a high disperse ability of the microstructure (average size of crystals is 5-7 $\mathrm{nm}$ [13]) and operating characteristics.

The high wear resistance of multicomponent coatings is associated with an increase in hardness and higher resistance to plastic deformation. Thus, the creation of these systems in a form of coatings and investigation of their tribotechnical characteristics $[14-16]$ is of high interest.

The aim of the work is to determine the effectiveness of the method of vacuum-arc deposition for obtaining materials with high mechanical properties from compositions containing strong nitride forming components during their deposition under various pressures (0.4 and $0.09 \mathrm{~Pa})$ in the nitrogen atmosphere [17].

\section{MATERIALS AND METHODS OF INVESTIGATION}

In this paper, transition metals $(\mathrm{Ti}, \mathrm{Zr}, \mathrm{Hf}, \mathrm{V}, \mathrm{Nb}$, and Ta) with high heat of nitrides formation $[8,9]$ are used as the basic elements of high-entropy alloys. 
Table 1. Physicotechnological parameters of coating deposition

\begin{tabular}{c|c|r|l}
\hline Series no. & $I_{\mathrm{a}}, \mathrm{A}$ & $U_{\mathrm{b}}$ & $P, \mathrm{~Pa}$ \\
\hline 1 & 110 & 150 & 0.4 \\
2 & 110 & 150 & 0.09 \\
3 & 95 & 70 & 0.09 \\
4 & 95 & 70 & 0.5 \\
\hline
\end{tabular}

Coatings were deposited using the vacuum-arc method with the evaporation of the cathode from $\mathrm{Ti}-\mathrm{Zr}-\mathrm{Hf}-\mathrm{V}-\mathrm{Nb}-\mathrm{Ta}$ high-entropy alloy in the atmosphere of a nitrogen reacting gas. Parameters of deposition are presented in Table 1 , where $I_{\mathrm{a}}$ is the arc current, $U_{\mathrm{b}}$ is the constant bias potential on the substrate, $P$ is the pressure of nitrogen during deposition. Based on preliminary studies, the values of $U_{\mathrm{b}}$ were set equal to -70 and $-150 \mathrm{~V}$ (see, e.g., [9]) to obtain optimal mechanical properties of coatings. Substrates were made of R6M5 $(H R C=62)$ steel with diameters of $45 \mathrm{~mm}$, thicknesses of $4.0 \mathrm{~mm}$, and surface roughness of $R_{a}=0.08 \mu \mathrm{m}$. The thickness of coatings was $8 \mu \mathrm{m}$ and roughness was $R_{a}=0.36 \mu \mathrm{m}$.

The investigation of the wear resistance of multicomponent coatings was conducted using tribometry methods using an automated friction machine (Tri-

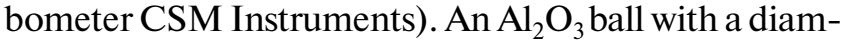
eter of $6.0 \mathrm{~mm}$ was used as a counterbody. Using optical and raster scanning microscopy (NanoScan 450), the nature of the wear of the sample and the counterbody was investigated. The measurement of the vertical section of wear grooves on the sample were performed using a profilometer in four diametrically and orthogonally opposite regions, and the mean values of groove section area and depth were determined. The element composition of coatings was analyzed using the energy dispersion method.

The hardness of coatings was studied using DM-8 hardness meter. In order to reduce the influence of the drop fraction (roughness), as well as for more precise measurements, some of the coatings were polished after deposition. Studies of the structure and phase were performed using a DRON-3M diffraction meter in $\mathrm{Cu} K_{\alpha}$ radiation. A graphite monochromator was installed at the secondary beam (in front of the detec- tor) for the monochromation of the recorded radiation. Studies of the phase composition and structure, including the texture and subtextures, were performed using traditional techniques of X-ray diffraction analysis by analyzing the position, intensity, and shape of profiles of diffraction reflections.

\section{RESULTS AND DISCUSSION}

Important factors that determine the functional characteristics of coatings include the element and phase compositions and their structure. The results of an elementary analysis of the coatings (TiZrHfVNbTa) N are shown in Table 2. As shown in Table 2, the relatively low bias potential of $-70 \mathrm{~V}$ results in the less effective formation of nitride (less nitrogen is bonded in the coating under low pressure, series no. 3).

An analysis of diffraction spectra shows that coatings obtained under a low pressure of nitrogen of $0.09 \mathrm{~Pa}$ and relatively high of $0.4 \mathrm{~Pa}$ are characterized by nitride with a face-centered cubic metal sublattice ( $\mathrm{NaCl}$ structural type) as a basic phase and the low concentration (up to $7 \mathrm{vol} \%$ ) of a component with body centered cubic crystal sublattice apparently related to presence of a drop fraction in the coating.

As in case of $U_{\mathrm{b}}=-70 \mathrm{~V}$ and $U_{\mathrm{b}}=-150 \mathrm{~V}$, coatings obtained at a low pressure of $0.09 \mathrm{~Pa}$ are characterized by an almost nontexturized structure (Fig. 1, spectrum 1). Increased up to (0.4-0.5) Pa pressure of nitrogen results in appearance of a texture with [111] axis in case of $U_{\mathrm{b}}=-70 \mathrm{~V}$ and bi-texture structure with axial texture with [111] and [110] axes at $U_{\mathrm{b}}=-150 \mathrm{~V}$ (Fig. 1, spectrum 2).

Studies using the approximation method of substructure characteristics showed that, under the lowpressure impingement of a growing coating by charged accelerated particles that hardly impact each other, the development of high microdeformation reaches a value of $1.09 \%$ at a small average size of crystals of around $10 \mathrm{~nm}$ at $U_{\mathrm{b}}=-150 \mathrm{~V}$ and a value of $0.83 \%$ at an average size of crystals of $47 \mathrm{~nm}$ at $U_{\mathrm{b}}=-70 \mathrm{~V}$.

An in crease in pressure to $0.4-0.5 \mathrm{~Pa}$ defines the large loss of energy for impacts in the space between electrons and results in a decrease in the microdeformation in formed crystals to $0.88 \%$ at an average crystal size of $80 \mathrm{~nm}$ for $U_{\mathrm{b}}=-150 \mathrm{~V}$ and a decrease to $0.63 \%$ at an average crystal size at an average crystallite size of $95 \mathrm{~nm}$ at at $U_{\mathrm{b}}=-70 \mathrm{~V}$ in condensable coatings.

Table 2. Element composition of multicomponent coatings (at \%)

\begin{tabular}{c|c|c|c|c|c|r|c}
\hline Series no. & $\mathrm{N}$ & $\mathrm{Zr}$ & $\mathrm{Nb}$ & $\mathrm{Ti}$ & $\mathrm{V}$ & $\mathrm{Hf}$ & $\mathrm{Ta}$ \\
\hline 1 & 55.48 & 8.13 & 7.73 & 7.85 & 6.32 & 9.53 & 4.96 \\
2 & 52.75 & 8.49 & 8.1 & 9.77 & 6.59 & 9.47 & 4.83 \\
3 & 36.41 & 11.77 & 10.84 & 14.52 & 7.91 & 10.71 & 6.84 \\
4 & 54.72 & 7.74 & 8.44 & 10.82 & 5.91 & 8.09 & 4.28 \\
\hline
\end{tabular}




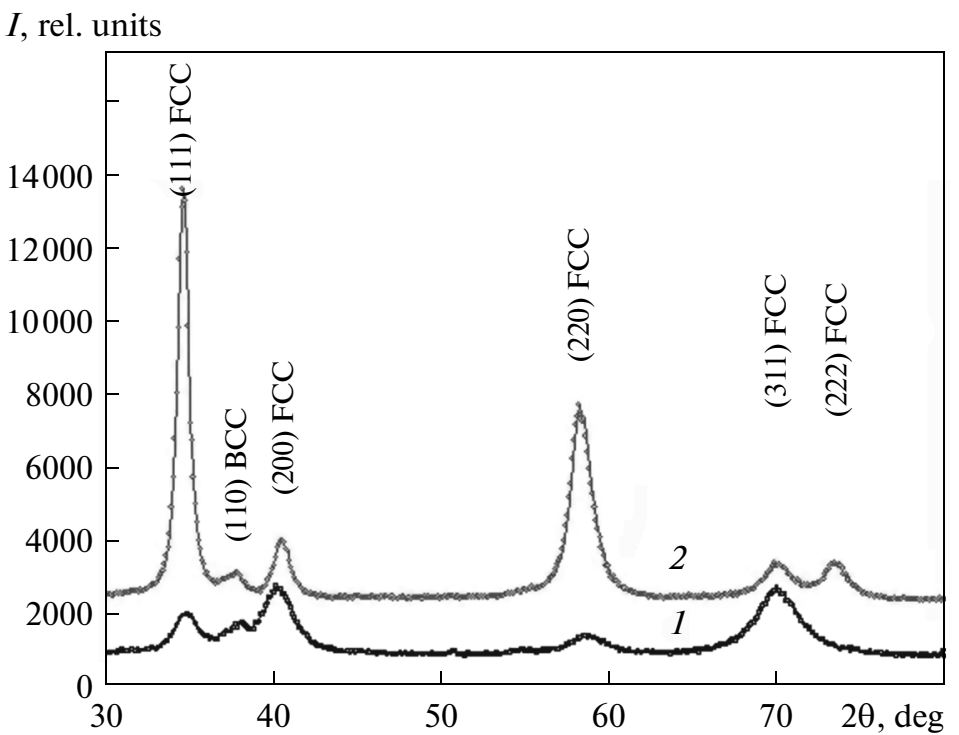

Fig. 1. Diffraction spectra of multicomponent coatings based on (TiZrHfVNbTa) N deposited under different partial pressures of nitrogen reacting gas and negative bias potential $150 \mathrm{~V}$ : (1) $P=0.09 \mathrm{~Pa}$ (series no. 2); (2) $0.4 \mathrm{~Pa}$ (series no. 1).

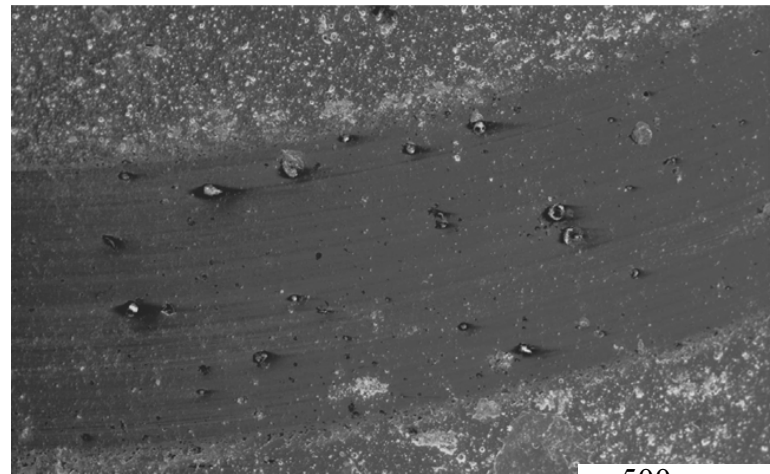

(a)

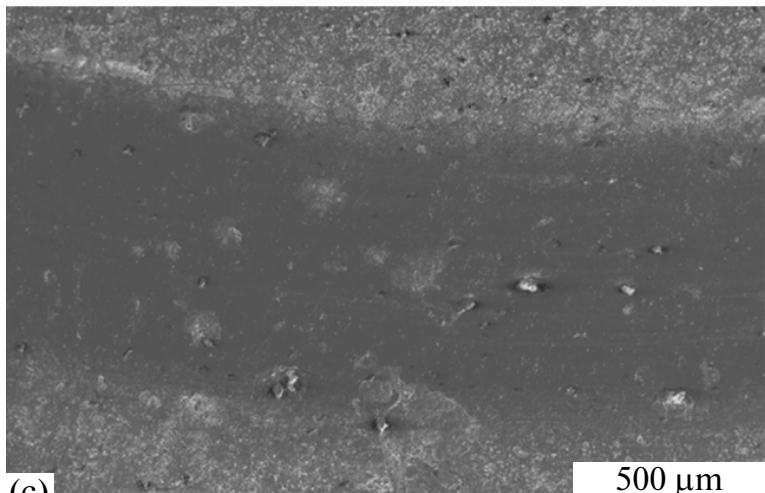

(c)

Fig. 2. Images of tracks of coatings wear: (a) $P=0.4 \mathrm{~Pa}$; (b) $P=0.09 \mathrm{~Pa}\left(U_{\mathrm{b}}=-150 \mathrm{~V}\right)$, (c) $P=0.09 \mathrm{~Pa}\left(U_{\mathrm{b}}=-70 \mathrm{~V}\right)$.

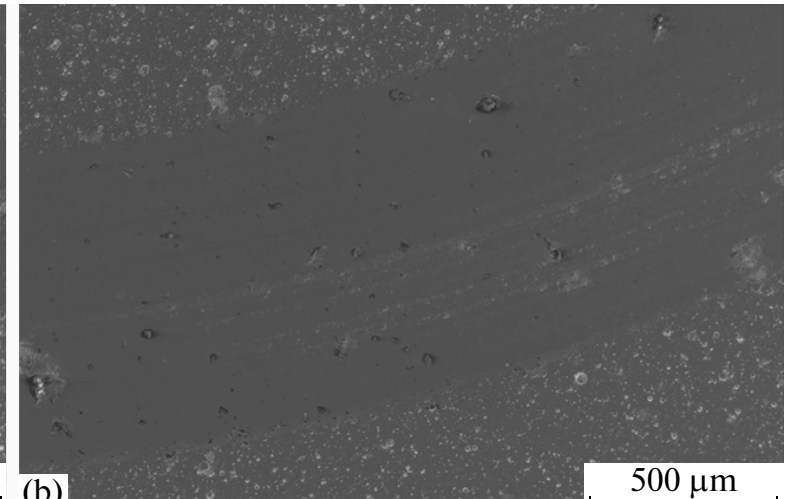

(b)

$500 \mu \mathrm{m}$
One of the most universal characteristics for the express analysis of mechanical properties is hardness. The measured hardness of coatings (TiZrHfVNbTa) N was $H V_{0.2}=51 \mathrm{GPa}$ at $P=0.4 \mathrm{~Pa}, H V_{0.2}=38 \mathrm{GPa}$ at $P=0.09 \mathrm{~Pa}$ for coatings obtained at $U_{\mathrm{b}}=-150 \mathrm{~V}$ and 
Table 3. Element composition of surface of friction tracks of coatings (at \%)

\begin{tabular}{c|c|c|c|c|c|c|c|c}
\hline Series no. & $\mathrm{N}$ & $\mathrm{O}$ & $\mathrm{Zr}$ & $\mathrm{Nb}$ & $\mathrm{Ti}$ & $\mathrm{V}$ & $\mathrm{Hf}$ & $\mathrm{Ta}$ \\
\hline 1 & 51.48 & 2.49 & 8.48 & 8.17 & 8.11 & 6.64 & 9.39 & 5.2 \\
2 & 50.63 & 1.97 & 8.73 & 8.18 & 10.23 & 7.03 & 8.67 & 4.54 \\
3 & 34.81 & 15.73 & 10.26 & 10.42 & 15.36 & 4.8 & 4.1 & 4.52 \\
\hline
\end{tabular}

Table 4. Element analysis of wear products (at \%)

\begin{tabular}{c|c|c|c|c|c|c|c|c|c|c}
\hline Series no. & $\mathrm{N}$ & $\mathrm{O}$ & $\mathrm{Al}$ & $\mathrm{Hf}$ & $\mathrm{Zr}$ & $\mathrm{Nb}$ & $\mathrm{Ti}$ & $\mathrm{V}$ & $\mathrm{Ta}$ & $\mathrm{Fe}$ \\
\hline 1 & 27.26 & 49.07 & 2.98 & 3.4 & 3.76 & 3.65 & 3.57 & 2.93 & 2.91 & 0.47 \\
2 & 23.01 & 51.67 & 8.85 & 2.59 & 2.97 & 2.86 & 3.2 & 2.24 & 2.18 & 0.43 \\
3 & - & 75.76 & 6.72 & - & 4.72 & 4.51 & 8.28 & - & - & - \\
4 & 17.92 & 37.28 & 9.93 & 4.69 & 5.58 & 5.81 & 9.37 & - & - & 9.42 \\
\hline
\end{tabular}

rity and do not wear down to substrates. Comparison with results of element analysis show that, in the process of friction, oxidation-mechanical wear takes place under the influence of the ambient atmosphere and dynamic effects between contacting materials [18-20].

During wear on the surface of friction tracks an oxidation film may form, which is indicated by results of $\mathrm{X}$-ray energy disperse analysis of wear products (Fig. 3, Table 4).

Results of the element analysis of wear products are presented in Table 4 and the image of the wear products in Fig. 3.

The obtained results show that, in coatings obtained using lower bias potential $(-70 \mathrm{~V})$, stronger contamination of surface by oxygen takes place, which, in this case, can be associated with the lower value of microdeformation that develops.

These products of wear protect friction surface against wear, as well as the formation of oxides with metals such as $\mathrm{Ti}, \mathrm{Nb}$, and $\mathrm{Hf}$ products of oxidation wear, may have high hardness and result in abrasive wear. In connection with this, important data of mechanical properties is the coefficient of friction and wear resistance compared to the wear of substrates and removal of counterbody material.

Values of the coefficient of friction $\mu$ and wear resistance obtained during tests of coating (TiZrHfVNbTa) $\mathrm{N}-\mathrm{Al}_{2} \mathrm{O}_{3}$ are shown in Table 5.

For all samples, the coefficient of friction is $\sim 0.9$. These high values can be explained by the drop fraction that is inherent to coatings obtained from the plasma beam. Based on the obtained results, it can be noted that, under the conditions of friction realized in our experiments, multicomponent coatings based on (TiZrHfVNbTa) $\mathrm{N}$ have higher wear resistance. The highest wear resistance is achieved in coatings obtained at $P=0.09 \mathrm{~Pa}$ and $U_{\mathrm{b}}=-150 \mathrm{~V}$, for which the absence of a dominant orientation of crystallite grains and the highest value of microdeformation are typical.
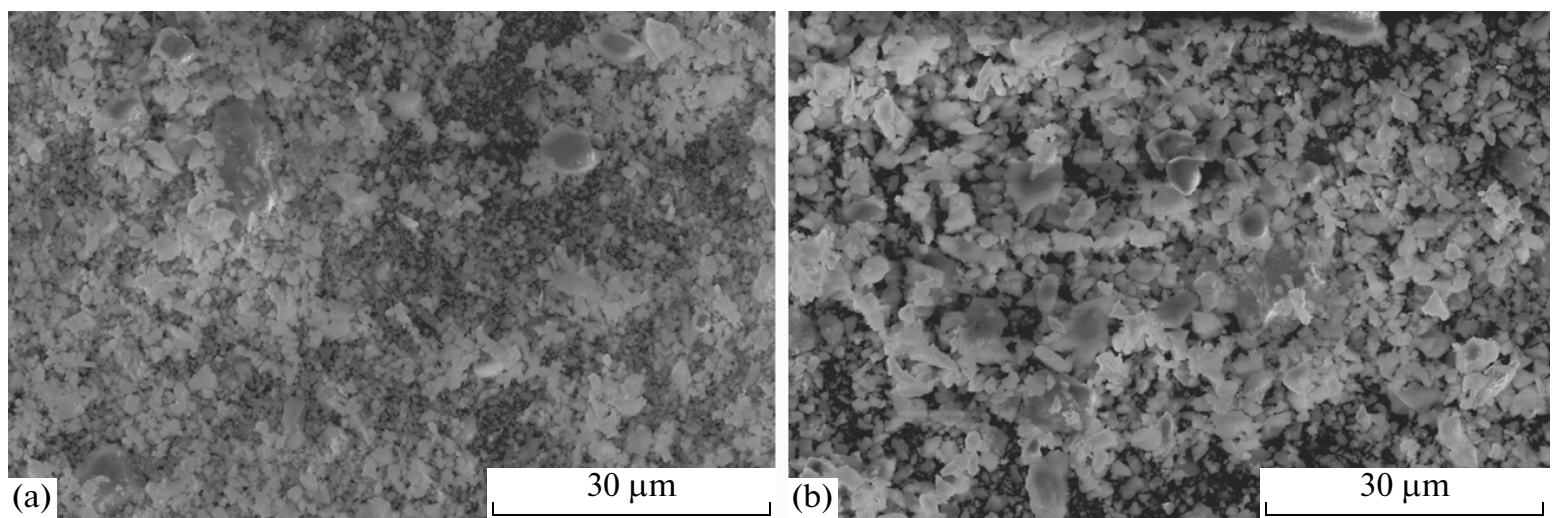

Fig. 3. Image of (TiZrHfVNbTa) N coatings wear products: (a) coatings of series no. 1; (b) coatings of series no. 2. 
Table 5. Tribological characteristics of systems R6M5 substrate $-\mathrm{Al}_{2} \mathrm{O}_{3}$ and (TiZrHfVNbTa) N coating $-\mathrm{Al}_{2} \mathrm{O}_{3}$

\begin{tabular}{l|c|c|c|c}
\hline \multirow{2}{*}{ Sample/coating } & \multicolumn{2}{|c|}{ Coefficient of friction $\mu$} & \multicolumn{2}{c}{ Factor of wear, $\mathrm{mm}^{3} \mathrm{~N}^{-1} \mathrm{~mm}^{-1}$} \\
\cline { 2 - 4 } & initial & during tests & counterbody $\left(\times 10^{-6}\right)$ & sample $\left(\times 10^{-5}\right)$ \\
\hline R6M5 steel & 0.211 & 0.474 & 4.69 & 5.12 \\
(TiZrHfVNbTa)N, (series no. 1) & 0.611 & 0.901 & 8.74 & 2.74 \\
(TiZrHfVNbTa)N, (series no. 2) & 0.507 & 0.864 & 9.92 & 2.12 \\
(TiZrHfVNbTa)N, (series no. 3) & 0.687 & 0.980 & 7.11 & 3.27 \\
(TiZrHfVNbTa)N, (series no. 4) & 0.701 & 1.010 & 6.98 & 3.83 \\
\hline
\end{tabular}

In the case of $U_{\mathrm{b}}=-70 \mathrm{~V}$, this tendency remains, although, for a higher degree of wear, which in this case can also be associated to a lower (in absolute value) degree of microdeformation.

\section{CONCLUSIONS}

(1) The influence of the pressure of the nitrogen atmosphere during the deposition of nitride coatings based on high-entropy $\mathrm{Ti}-\mathrm{Zr}-\mathrm{Hf}-\mathrm{V}-\mathrm{Nb}-\mathrm{Ta}$ alloys on their hardness, coefficient of friction, and wear resistance is analyzed.

(2) It was determined that, when pressure increased from 0.09 to $0.4 \mathrm{~Pa}$, in addition to appearance of bitexture structure [111] and [110] axes, the hardness increased from 38 to $51 \mathrm{GPa}$.

(3) Based on an analysis of the nature of the wear, it was defined that, during friction, the nitrogen is partially removed from the combination and replaced by oxygen. This process was accompanied by the enrichment of the contacting surface by atoms of $\mathrm{Ti}, \mathrm{Nb}$, and Ta with high heat of oxides formation.

(4) Oxidation-mechanical wear results in the domination of oxide components in wear products.

(5) The highest resistance to wear is attributed to coatings (TiZrHfVNbTa) N obtained under a pressure of $0.09 \mathrm{~Pa}$. In this case, the coating is characterized by high microdeformation, the absence of texture, and corresponding anisotropy of properties.

\section{ACKNOWLEDGMENTS}

The present paper was carried out with financial support from the Ministry of Education and Science of the Russian Federation as a governmental task in the field of scientific activity.

\section{REFERENCES}

1. Myshkin, N.K. and Petrokovets, M.I., Trenie, smazka, iznos (Friction, Lubrication, Wear), Moscow: Fizmatlit, 2007.

2. Sovremennaya tribologiya: Itogi i perspektivy (Contemporary Tribology: Results and Prospects), Frolov, K.V., Ed., Moscow: LKI, 2008.
3. Sobol', O.V., Andreev, A.A., Grigoriev, S.N., Gorban', V.F., Volosova, M.A., Aleshin, S.V., and Stolbovoy, V.A., Physical characteristics, structure and stress state of vacuum-arc tin coating, deposition on the substrate when applying high-voltage pulse during the deposition, Probl. Atom. Sci. Technol., Ser.: Physics of Radiation Effect and Radiation Materials Science, 2011, no. 4, pp. 174-177.

4. Sobol', O.V., Andreev, A.A., Grigoriev, S.N., Gorban', V.F., Volosova, M.A., Aleshin, S.V., and Stolbovoi, V.A., Effect of high-voltage pulses on the structure and properties of titanium nitride vacuum-arc coatings, Metal Sci. Heat Treat., 2012, vol. 54, pp. 195203.

5. Sobol, O.V., Andreev, A.A., Grigoriev, S.N., Volosova, M.A., and Gorban', V.F., Vacuum-arc multilayer nanostructured TiN/Ti coatings: Structure, stress state, properties, Metal Sci. Heat Treat., 2012, vol. 54, pp. 28-33.

6. Shumikhina, E.M. and Grigor'ev, S.N., Increasing of energoeffectivity of auxiliary equipment of devices for vacuum-plasma infliction of coating by automation means, Vestnik Mos. Gos. Tekhn. Univ. Stankin, 2010, no. 3, pp. 82-85.

7. Metel, A.S., Grigoriev, S.N., Melnik, Yu.A., and Bolbukov, V.P., Characteristics of a fast neutral atom source with electrons injected into the source through its emissive grid from the vacuum chamber, Instrum. Exp. Tech., 2012, vol. 55, no. 2, pp. 288-293.

8. Andreev, A.A., Gorban', V.F., Krapivka, N.A., Stolbovoi, V.A., Serdyuk, I.V., and Fil'chikov, V.E., Reproducibility of the single-phase structural state of the multielement high-entropy $\mathrm{Ti}-\mathrm{V}-\mathrm{Zr}-\mathrm{Hf}$ system and related superhard nitrides formed by the vacuum-arc method, Tech. Phys. Lett., 2012, vol. 38, no. 7, pp. 616619.

9. Sobol', O.V., Andreev, A.A., Voevodin, V.N., Gorban', V.F., Grigor'ev, S.N., Volosova, M.A., and Serdyuk, I.V., Effect of shift and pressure nitrogen potential on structure-stressed state and properties of nitride coatings produced by evaporation of highentropy alloys by vacuum-arc method, Vopr. At. Nauki Tekhn., Chist. Mater. Vakuum. Tekhn., 2014, no. 1 pp. 141-146.

10. Pogrebnjak, A.D. and Beresnev, V.M., Hard nanocomposite coatings, their structure and properties, in Nanocomposites. New Trends and Developments, 2012, Ch. 6, pp. 123-160. 
11. Azarenkov, N.A., Sobol', O.V., Beresnev, V.M., Pogrebnyak, A.D., Kolesnikov, D.A., Turbin, P.V., and Toryanik, I.N., Vacuum-plasma coatings based of the multielement nitrides, Metallofiz. Nov. Tekhnol., 2013, vol. 35, pp. 1061-1084. http://apps.webofknowledge.com/full_record.do?product=UA\&search_mode $=$ Refine \&qid $=\overline{13} \& \mathrm{SID}=$ P1mgDWisgqVkqewvJYq $\&$ page $=$ $1 \&$ doc $=1 \&$ cacheurlFromRightClick $=$ no

12. Firstov, S.A., Gorban', V.F., Krapivka, N.A., and Pechkovskii, E.P., Hardening and mechanical properties of as-cast high-entropy alloys, Komp. Nanostrukt., 2011, no. 2, pp. 5-20.

13. Pogrebnyak, A.D., Bondar', O.V., Beresnev, V.M., Abadias, G., Chartier, P., Takeda, Y., Oyoshi, K., Sobol', O.V., Andreev, A.A., Mukushev, B.A., and Yakushchenko, I.V., The effect of the deposition parameters of nitrides of high-entropy alloys (TiZrHfVNb)N on their structure, composition, mechanical and tribological properties, Journal of Superhard Materials, 2013, vol. 35, pp. 356-368.

14. Serdyuk, I.V., Sobol, O.V., Andreev, A.A., Voevodin, V.N., Gorban, V.F., Grigor'ev, S.N., and Volosova, M.A., The bias potential and pressure nitrogen effect on structural stress on the structure-stressed state and properties of nitride coatings produced from high-entropy alloys by the vacuum arc technique, Probl. Atom. Sci. Technol., Ser.: Pure Mater. Vacuum Technol., 2014, no. 1, pp. 141-146.
15. Grigoriev, S.N., Melnik, Yu.A., Metel, A.S., Panin, V.V., and Prudnikov, V.V., A compact vapor source of conductive target material sputtered by $3-\mathrm{Kev}$ ions at 0.05-Pa pressure, Instrum. Exp. Tech., 2009, vol. 52, no. 5, pp. 731-737.

16. Andreev, A.A., Grigor'ev, S.N., Gorban', V.F., Stolbovoi, V.A., and Shulaev, V.M., Vacuum-arc nanostructured TiN coatings, Vestn. Mos. Gos. Tekhn. Univ. Stankin, 2010, no. 3, pp. 14-17.

17. Metel, A.S., Grigoriev, S.N., Melnik, Yu.A., and Bolbukov, V.P., Broad beam sources of fast molecules with segmented cold cathodes and emissive grids, Instrum. Exp. Tech., 2012, vol. 55, no. 1, pp. 122-130.

18. Khomenko, A.V. and Lyashchenko, Ya.A., Statistical theory of the boundary friction of atomically flat solid surfaces in the presence of a lubricant layer, Phys.-Usp., 2012, vol. 55, pp. 1008-1034.

19. Grigoriev, S.N., Mandel, A.M., Oshurko, V.B., Solomakho, G.I., and Veselko, S.G., On the mechanism of friction reduction of nanosize multilayer coatings, Metallofiz. Nov. Tekhnol., 2013, vol. 35, no. 7, pp. 933-942.

20. Andreev, A.A., Volosova, M.A., Gorban, V.F., et al., The use of pulsed ion stimulation to modify the stressed structure state and mechanical properties of vacuumarc tin coatings, Metallofiz. Nov. Tekhnol., 2013, vol. 35, no. 7, pp. 953-963.

Translated by S. Saveleva 